\title{
IMPLEMENTASI SENAM DYSMENORRHOEA PADA REMAJA PREMENSTRUASI SYNDROME DI SMAN 15 BANDAR LAMPUNG
}

DOI: https://doi.org/10.33024/jkpm.v4i4.4755

$$
\text { Sunarsih }^{1^{*}} \text {, Anita Bustami }{ }^{2} \text {, Siti Fatonah }{ }^{3}
$$

1-3 Poltekkes Tanjungkarang Jurusan Keperawatan

Disubmit: 02 Juni 2021 Diterima: 4 Agustus 2021 Diterbitkan: 04 Agustus 2021

Email Korespondensi: sunarsihkarim@gmail.com

\begin{abstract}
ABSTRAK
Angka kejadian dismenorrhoea di Indonesia tahun 2011 sebanyak 64,25\%, terdiri dari 54,89\% mengalami dysmenorrhoea primer dan hanya 20\% yang tidak mengalami dismenorrhoea. Remaja putri di SMAN 15 sejumlah 256 Siswa, remaja putri sejumlah 176 orang yang mengeluhkan nyeri haid dari sedang sampai dengan berat. Dismenorrhoea sangat mengganggu aktivitas belajar siswa dan emosi remaja. Permasalahan yang muncul pada remaja adalah ketidaknyamanan dalam melakukan pembelajaran, sehingga angka ketidakhadiran di kelas menjadi lebih banyak. Pengabdian kepada masyarakat yang dilakukan bertujuan untuk mengurangi nyeri melalui senam dismenorrhoea dan mengupayakan siswa dapat beradaptasi dengan nyeri haid yang dialami. Hasil pengabdian kepada masyarakat sejumlah 150 siswa dan guru telah diberikan informasi tentang fisiologi haid dan permasalahannya serta upaya mengatasinya, termasuk mendapatkan leaflet dan video senam dismenorrhoea. Siswa dan guru antusias mengikuti kegiatan penyuluhan, interaksi aktif berjalan baik narasumber maupun peserta. Hasil penyuluhan diharapkan guru dan siswa yang dilatih senam dapat mengatasi permasalahan dismenorrhoea dan memberikan informasi kepada teman sebaya jika mengalami dismenorrhoea.

Kata kunci: Dysmenorrhoea, pre menstruasi, senam
\end{abstract}

\section{ABSTRACT}

The incidence of dysmenorrhoea in Indonesia in 2011 was $64.25 \%$, consisting of $54.89 \%$ experiencing primary dysmenorrhoea and only $20 \%$ experiencing dysmenorrhoea. 256 students and 176 young women complained of moderate to severe menstrual pain. Dysmenorrhoea very disturbs student learning activities and adolescent emotions. The problem that arises in adolescents is the discomfort in learning, so that the number of absenteeism in class is higher. The community service that is carried out aims to reduce pain through dysmenorrhoea exercise and strive for students to adapt to menstrual pain experienced. The results of community service, a number of 150 students and teachers, have been given information about the physiology of menstruation and its problems and efforts to overcome them, including obtaining leaflets and videos of dysmenorrhoea exercise. Students and teachers enthusiastically participate in counseling activities, active interaction runs both the resource person and the participants. The results of the counseling are expected that teachers and students who are trained in gymnastics can overcome 
dysmenorrhoea problems and provide information to peers if they experience dysmenorrhea.

Key words: Dysmenorrhoea, pre menstruation, exercise

\section{PENDAHULUAN}

Kegiatan Pengambas PKM dilaksanakan di Sekolah Mitra Poltekkes Tanjungkarang yaitu SMAN 15 Bandar Lampung. SMA Negeri 15 Bandar Lampung memiliki 6 kelas yaitu kelas X MIA, X HS, XI IPA, XI IPS, XII IPA dan XII IPS dengan jumlah seluruh siswanya 256 siswa, dimana terdapat 179 siswa wanita yang didapatkan mengalami dismenorrhea. Hasil wawancara dengan siswa diperoleh data terhadap 30 siswi Kelas X, SMAN 15 Bandar Lampung, didapatkan data sebanyak $87 \%$ mengalami dysmenorrhoea, yang diantaranya 4 mahasiswi $(13,3 \%)$ mengalami dysmenorrhoea berat, 17 mahasiswi $(56,7 \%)$ mengalami dysmenorrhoea sedang dan 9 mahasiswi (30\%) mengalami dysmenorrhoea ringan. Dismenorrhea membuat aktifitasnya terganggu dan lebih banyak istirahat ditempat tidur, sulit berkonsenterasi pada saat belajar dan terkadang mereka izin tidak mengikuti kegiatan belajar.

Potensi mitra SMA Negeri 15 dikembangkan oleh Tim Pengabmas PKM Poltekkes Tanjungkarang adalah terdapat gedung aula sekolah yang dapat digunakan untuk penyuluhan senam dismenorrhea, kendaraan operasional sekolah, alat penunjang seperti sound system, ruang UKS dan Wifi sebagai media untuk penyuluhan senam dysmenorrhoea, serta guru-guru untuk bergabung terkait penanganan dismenorrhea dengan melakukan senam dismenorrhea.

Ciri kedewasaan perempuan adalah menstruasi yang biasanya diawali pada usia remaja (9-12 tahun) dan sejak saat itulah perempuan akan terus mengalami menstruasi sepanjang hidupnya, setiap bulan hingga mencapai usia 45-55 tahun (Anurogo, 2011:10). Menstruasi atau yang kita kenal dengan istilah haid adalah kejadian alamiah yang terjadi pada wanita normal, ini terjadi karena terlepasnya lapisan endometrium uterus yang biasanya terjadi setiap bulan dengan siklus setiap orang berbeda, ada yang 28 hari, ada pula yang kurang bahkan lebih dari itu (Andira, 2010:30).

Bagi beberapa orang menstruasi menjadi hal yang biasa-biasa saja namun bagi sebagian wanita tidak demikian adanya. Berbagai macam gangguan muncul beberapa hari menjelang menstruasi atau saat menstruasi berlangsung. Salah satunya adalah nyeri pada saat menstruasi yang disebabkan oleh kejang otot uterus atau biasa disebut dengan istilah dysmenorrhoea (Mitayani, 2011:211). Dysmenorrhoea adalah istilah medis untuk haid yang terasa nyeri dan sekitar $75 \%$ wanita mengalami dysmenorrhoea pada suatu saat sepanjang usia reproduksinya. Terkadang dysmenorrhoea dapat disertai dengan rasa mual, muntah, diare dan kram perut, beberapa wanita bahkan pingsan dan mabok, keadaan ini muncul cukup hebat sehingga menyebabkan penderita mengalami gangguan aktivitas untuk sementara (Stoppard, 2006:247). Baradero, Dayrit, Siswadi (2007:9) menyebutkan bahwa dysmenorrhoea dikelompokkan sebagai dysmenorrhoea primer dan dysmenorrhoea sekunder, saat tidak ada sebab yang dapat dikenali (dysmenorrhoea primer) dan saat ada kelainan jelas yang menyebabkannya (dysmenorrhoea sekunder).

Di Amerika Serikat diperkirakan hampir $90 \%$ wanita mengalami dysmenorrhoea, dan $10-15 \%$ di antaranya mengalami dysmenorrhoea berat, yang menyebabkan mereka tidak mampu melakukan kegiatan 
apapun. Penelitian di Swedia menjumpai $30 \%$ wanita menurun jumlah penghasilannya dikarenakan nyeri saat haid. Jurnal Occupation And Environment Medicine dalam Purwati (2011:4). Setiasih dalam Purwati (2011:5) mengatakan di Indonesia angka kejadian dysmenorrhoea sebesar 64,25\% yang terdiri dari 54,89\% dysmenorrhoea primer dan 9,36\% dysmenorrhoea sekunder. Survey oleh Jeffcoate hanya $20 \%$ wanita yang sama sekali tidak mengalami gangguan apapun pada saat menstruasi sedangkan PKRR (Persatuan Kesehatan Ramah Remaja) tahun 2007 menyebutkan bahwa permasalahan remaja Indonesia adalah seputar permasalahan mengenai gangguan menstruasi sebanyak $38,45 \%$.

Hasil studi terbaru yang dilakukan oleh Purwati (2011) menunjukan sebanyak 60,11\% siswi mengalami dysmenorrhoea diantaranya mengaku terganggu dalam konsentrasi belajar dan 5,05\% diantaranya mengaku absen dari pelajaran untuk beristirahat di UKS, bahkan terdapat siswi yang sampai tidak masuk sekolah karena sakit yang dirasakan saat menstruasi. Pada bulan Januari tahun 2009 dilakukan penelitian terhadap siswi di salah satu SMA Pulo Gadung, Jakarta Timur dan didapatkan sebanyak 54, mengalami dysmenorrhoea dan pada tahun 2010 di SMA Muhhamadiah 1 Kabupaten Sragen didapatkan sebanyak $54,9 \%$ yang mengalami dysmenorrhoea.

Berdasarkan data dari Dinas Kesehatan Provinsi Lampung tahun 2007 sebanyak 58,2\% mengalami dysmenorrhoea, yang menyebabkan ketidakmampuan remaja dalam melakukan tugasnya sehari-hari seperti sulit berkonsenterasi dan absen dari mata pelajaran akibat nyeri hebat. Nyeri saat haid tidak boleh dibiarkan begitu saja tanpa adanya upaya penanganan, karena mungkin saja gejala endometriosis bisa mempersulit wanita untuk hamil. Semua haid menimbulkan nyeri, namun yang tidak normal nyeri itu muncul menjelang menstruasi dan semakin berat saat haid pertama maupun kedua. Sebagai upaya penanganan untuk mengatasi dysmenorrhoea ini ada beberapa terapi yang bisa dilakukan, antara lain: terapi hormonal yang melibatkan dokter, terapi bahan alami serta mengikuti pola hidup sehat yang bisa dilakukan sendiri. Pola hidup sehat tentu dapat dilakukan berupa asupan gizi seimbang, istirahat cukup dan olahraga sesuai kebutuhan (Anurogo dan Wulandari, 2011:80).

Latihan-latihan olahraga yang ringan sangat dianjurkan untuk mengurangi dysmenorrhoea. Olahraga atau senam merupakan salah satu teknik relaksasi yang dapat digunakan untuk mengurangi nyeri. Hal ini disebabkan saat melakukan olahraga atau senam tubuh akan menghasilkan endorphin. Hormon ini dapat berfungsi sebagai obat penenang alami yang diproduksi otak dan susunan syaraf tulang belakang sehingga menimbulkan rasa nyaman (Meryn, 2005:160). Olahraga seperti senam juga bertujuan untuk meningkatkan sirkulasi darah agar tidak terjadi kram atau nyeri karena sirkulasi yang lambat dapat menyebabkan kram atau nyeri (Eileen, 2008:126).

Pengabdian kepada masyarakat ini didasari hasil penelitian sebelumnya oleh Sunarsih (2018) dengan judul pengaruh senam dysmenorrhoea terhadap premenstrual sindrome di SMA Negeri 15 Bandar Lampung tahun 2018. Hasil penelitian terdapat perbedaan yang bermakna skala nyeri haid sebelum dan sesudah dilakukan senam dysmenorhea pada siswi SMA Negeri 15 Bandar Lampung tahun 2018, $(p=0,00)$. Hal ini dapat dikatakan bahwa senam dysmenorrhea dapat menurunkan skala nyeri haid dengan dysmenorhea.

Berdasarkan fenomena diatas, maka penting dilakukan upaya meningkatkan pengetahuan remaja putri untuk mengetahui kondisi kesehatan terutama permasalahan Dysmenorrhea dan upaya penanganannya. 
Pemberdayaan pada anak remaja putri dalam menjaga kesehatan sangat diperlukan karena keberhasilan proses pendidikan juga dikarenakan berawal dari tubuh yang sehat dan tanpa nyeri. Maka tim keperawatan maternitas-anak pada jurusan keperawatan melakukan tridharma perguruan tinggi berupa kegiatan pengabdian kepada masyarakat dengan tema : "Implementasi senam dismenorhea pada remaja premenstruasi sindrome di SMA Negeri 15 Bandar Lampung tahun 2020".

\section{MASALAH}

Kegiatan Pengambas PKM dilaksanakan di Sekolah Mitra Poltekkes Tanjungkarang yaitu SMAN 15 Bandar Lampung, berdasarkan hasil wawancara dengan terhadap 30 siswi Kelas $X$ didapatkan data sebanyak $87 \%$ mengalami dysmenorrhoea, yang diantaranya 4 mahasiswi $(13,3 \%)$ mengalami dysmenorrhoea berat, 17 mahasiswi $(56,7 \%)$ mengalami dysmenorrhoea sedang dan 9 mahasiswi (30\%) mengalami dysmenorrhoea ringan. Dismenorrhea membuat aktifitas siswa terganggu dan lebih banyak istirahat ditempat tidur, sulit berkonsenterasi pada saat belajar dan terkadang mereka izin tidak mengikuti kegiatan belajar.

Potensi mitra SMA Negeri 15 dikembangkan oleh Tim Pengabmas PKM Poltekkes Tanjungkarang adalah terdapat gedung aula sekolah yang dapat digunakan untuk penyuluhan senam dismenorrhea, kendaraan operasional sekolah, alat penunjang seperti sound system, ruang UKS dan Wifi sebagai media untuk penyuluhan senam dysmenorrhoea, serta guru-guru untuk bergabung terkait penanganan dismenorrhea dengan melakukan senam dismenorrhea. Tujuan dilakukan senam dismenorrhoea adalah untuk meningkatkan kesehatan siswa dan upaya penanganan dismenorrhoea.

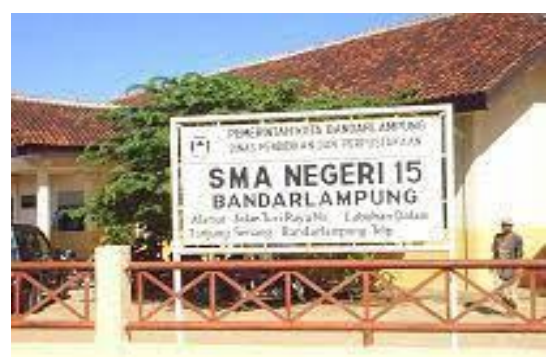

Gb. 1 Lokasi SMAN 15 Bandar Lampung

\section{METODE}

Pengabdian kepada masyarakat program kemitraan dalam upaya mengatasi permasalahan dismenorrhoe dilaksanakan secara daring dan luring, mulai tanggal 1 Juli sampai dengan 20 Agustus 2020. Metode pelaksanaan melalui:

1. Survei Lapangan: Survei dilakukan dengan berkunjung ke SMAN 15 dan melakukan diskusi dengan kepala sekolah, guru bagian kesiswaan dan 5 orang siswa remaja putri tentang pemahaman haid dan permasalahannya serta upaya penatalaksanaannya.

2. Koordinasi dengan fihak Sekolah: Koordinasi dilakukan dengan fihak SMAN 15 untuk diadakan pendidikan kesehatan terkait anemia dan MOA dalam pelaksanaan kegiatan Pengabmas dan kegiatan usaha kesehatan siswa di sekolah. 
3. Sosialisasi Program: Sosialisasi program dengan memasang spanduk dan pengumuman oleh mitra (SMP N 3) terkait kegiatan pelatihan dengan materi anemia remaja. Selanjutnya dilakukan pembentukan kader kesehatan remaja dan promosi kesehatan terkait anemia, serta penguatan UKS dalam pemberian pelayanan kesehatan pada siswa.

4. Pelaksanaan Program: Kegiatan Pengabdian kepada Masyarakat dilaksanakan dengan pembentukan kepanitiaan zoominar yang akan dilakukan, penyuluhan dan praktik senam dismenorhea pada siswa remaja putri, evaluasi dan diskusi dengan guru dan siswa. Sasaran kegiatan ini adalah 150 remaja putri dan guru SMAN 15 dan fihak sekolah (Kepala sekolah, guru dan pengelola UKS)

\section{HASIL DAN PEMBAHASAN}

Kegiatan pengabmas diikuti oleh sejumlah 150 siswa dan guru, pelaksanaan dilakukan melalui luring dan daring.

\section{Penyuluhan}

Kegiatan penyuluhan dilakukan melalui seminar ilmiah dengan topik Senam Dismenorrhoea dalam upaya mengatasi Pre menstrual syndrome. Sebelum pelaksanaan dilakukan pre test untuk mengetahui pemahaman remaja dan guru terkait materi yang disajikan, Selanjutnya dilakukan seminar daring dengan materi haid dan permasalahannya, serta senam dismenorrhoe dalam upaya mengatasi pre menstrual sindrom. Setelah narasumber menyampaikan materi, dilakukan diskusi dan tanya jawab, yang selanjutnya dilakukan post tes.

\section{Indikator Keberhasilan}

Indikator keberhasilan:

Diperolehnya 150 siswa remaja dan guru yang dapat melakukan senam dismenorhea dan memiliki sertifikat. Diperolehnya pemahaman yang sama tentang permasalahan haid dan penatalaksanaannya antara siswa dan guru khususnya guru pengelola UKS.Diperolehnya MOA sebagai mitra dalam pengabdian kepada masyarakat

\section{HASIL DAN LUARAN YANG DICAPAI}

Poltekkes Kemenkes Tanjungkarang dalam melakukan tridharma perguruan tinggi mempunyai kewajiban untuk membina kesehatan masyarakat. Jurusan keperawatan memiliki kelompok keilmuan kesehatan anak remaja yang terdiri dari dosen yang memiliki kemampuan sangat baik dalam kesehatan reproduksi dan permasalahan tumbuh kembang serta kesehatan anak. Potensi yang dimiliki dosen secara kognitif dan berbagai hasil penelitian harus diaplikasikan pada masyarakat utamanya kelompok berisiko seperti remaja putri yang organ reproduksinya harus berkembang, untuk berkembang sehat diperlukan adanya sumber pengetahuan terkait perubahan fisik dan gejala yang dialami pada saat menjelang dan saat menstruasi. Kegiatan siswa terkait pembelajaran dapat berlangsung baik, meskipun siswa sedang menstruasi dengan pre menstrual sindrome, dikarenakan siswa dapat 
mengatasi dengan senam dismenorhea. Untuk itu jurusan keperawatan Poltekkes Tanjungkarang layak untuk melaksanakan kegiatan pengabdian kepada masyarakat utamanya kepada remaja putri yang sedang tumbuh dan berkembang.

\section{Hasil Pengabmas}

Setelah dilakukan pertemuan dengan unsur pimpinan SMAN 15 Bandar Lampung disusunlah jadwal kegiatan untuk pelaksanaan penyuluhan kesehatan kepada 150 siswa dan guru. Kegiatan penyuluhan dilakukan melalui cloudx (daring), pertemuan dilakukan pada hari Jumat tanggal 7 Agustus 2020. Sehingga diperoleh sejumlah 140 orang siswa dan 10 guru sekolah yang mengikuti zoominar, telah memahami tentang haid dan dismenorrhoe, dan upaya mengatasi nyeri haid dengan senam dismenorrhoea. Siswa dan guru mendapatkan materi, leaflet dan video pembelajaran terkait senam dismenorhoea dan mendapat sertifikat.

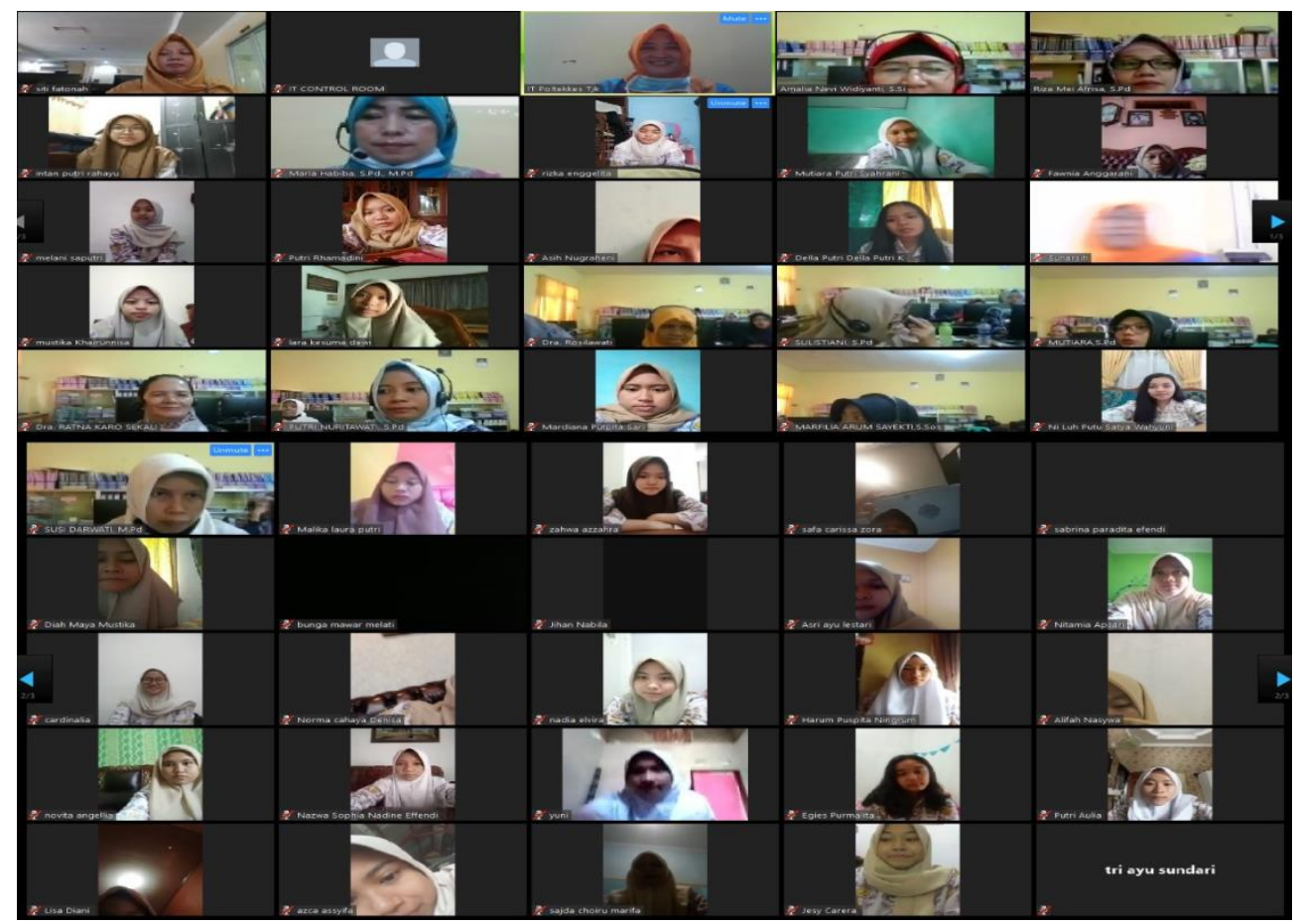

Gb. 2 Peserta webinar Senam Dismenorrhoea

Diperoleh pemahaman yang sama terhadap penatalaksanaan dismenorrhoea pada siswa dan guru dengan menggunakan senam dismenorrhoea. Adanya tim UKS yang kembali aktif meskipun di masa pandemi covid 19, dengan diketuai oleh ibu kepala sekolah dan ibu wakil kesiswaan yang selanjutnya tim akan melayani permasalahan kesehatan remaja. Diperolehnya MOA sebagai mitra dalam upaya kesehatan sekolah, khusus masalah kesehatan pada kelompok remaja.

\section{Luaran yang dicapai}

1) Diperolehnya 10 guru dan remaja sejumlah 140 orang siswa yang dapat menularkan pengetahuan tentang penatalaksanaan dismenorrhoea dan menjadi model dalam upaya mengatasi dismenorrhoea dengan melakukan senam. 
2) Diperolehnya MOU dan MOA terkait pembinaan kesehatan khususnya penanganan dismenorrhoea di SMAN 15 Bandar Lampung.

3) Tersusunnya RTL kegiatan selanjutnya terkait kesehatan remaja terutama permasalahan kesehatan reproduksi.

4) Artikel tentang kegiatan pengabmas dan publikasinya.

5) Leaflet dan video senam dismenorrhoea

Leaflet senam dismnorrhoea
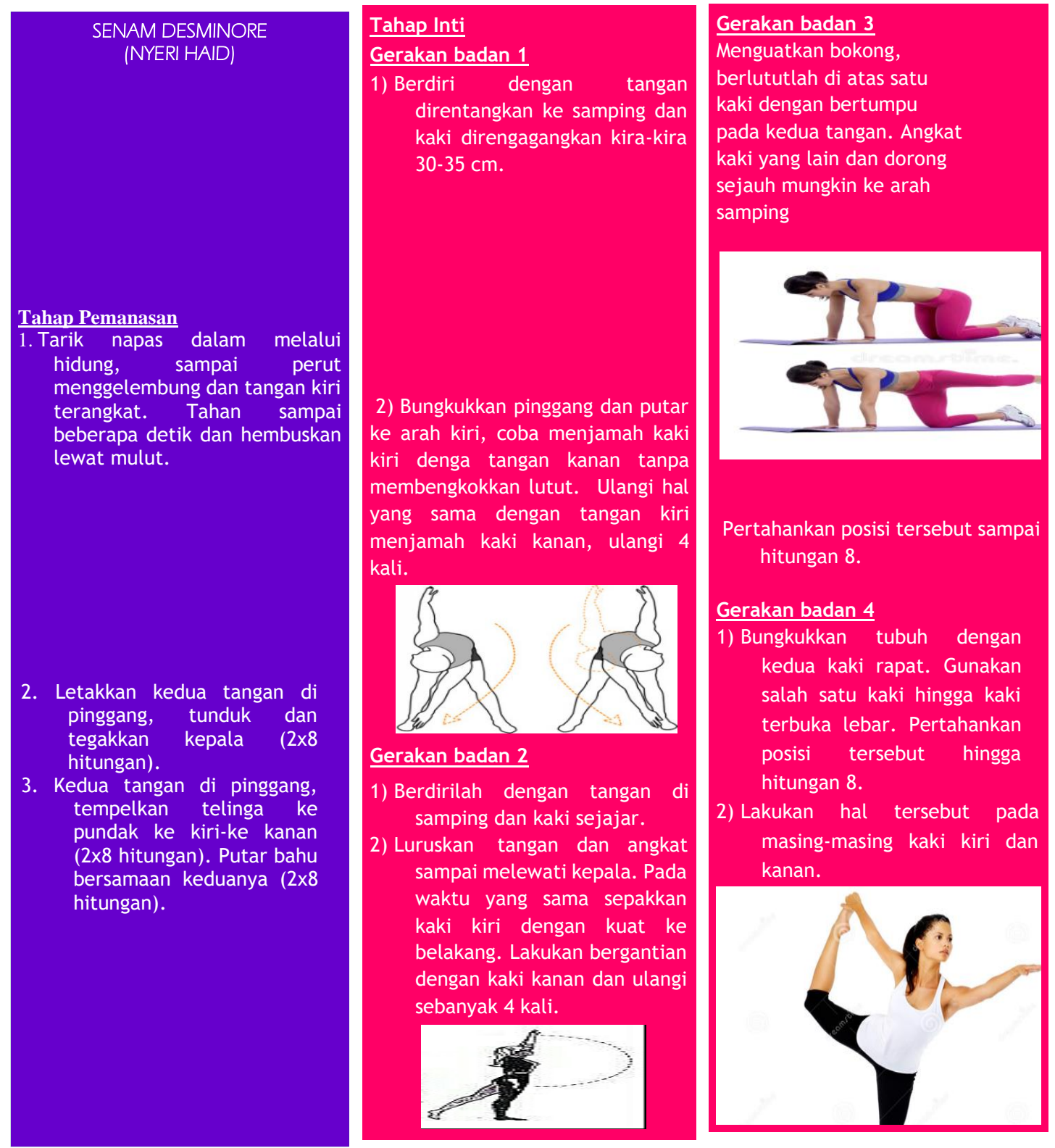


\section{KESIMPULAN}

1. Pengabdian kepada masyarakat pada kelompok remaja di SMA Negeri 15 Bandar Lampung, telah dilaksanakan terhadap 10 orang guru dan 140 siswa kelas 1-3, dan diperoleh kemampuan guru dan siswa yang memahami konsep haid dan penatalaksanaan nyeri haid dengan melakukan senam dismenorrhoea. Siswa memperoleh materi, leaflet dan video senam dimenorrhoea, serta mendapatkan sertifikat seminar.

2. Terjalin kerjasama MOU dan MOA dengan Poltekkes Tanjungkarang) khususnya keberlanjutan pengabmas di SMAN 15 Bandar Lampung terkait kesehatan reproduksi remaja putri.

3. Publikasi artikel terkait pengabdian kepada masyarakat melalui jurnal pengabmas.

\section{DAFTAR PUSTAKA}

Andarmoyo, Sulistyo. (2013). Konsep dan Proses Keperawatan Nyeri. Jogjakarta: Ar-Ruzz Media. 127 halaman.

Andira, Dita. (2010). Seluk Beluk Kesehatan Reproduksi Wanita. Jogjakarta: A Plus Books. 164 halaman.

Anurogo, Dito., Wulandari, Ari. (2011). Cara Jitumengatasi Nyeri Haid. Yogyakarta: Andi. 194 halaman.

Baradero, Mary., Dayrit, Wilfrid Mary; Siswadi, Yakobus. Seri Asuhan Keperawatan Klien Gangguan Sistem Reproduksi dan Seksualitas. Jakarta:. 122 halaman.

Baziad, Ali. (2008). Endokrinologi Ginekologi. Jakarta: Media Aesculapius. Brayshow, Eileen. 2007. Senam Hamil dan Nifas. Jakarta: EGC. 178 halaman.

Dahlan, Muhammad Sopiyudin. (2009). Statistik untuk Kedokteran dan Kesehatan. Jakarta: Salemba Medika. 272 halaman

El Manan. (2013). Kamus Cerdik Kesehatan Wanita. Jogjakarta: Flash Books.224 halaman.

Joseph \& Nugroho, (2010). Catatan Kuliah Ginekologi dan obstetri (Obsgyn). Yogyakarta: Nuha Medika.

Kurniawati, Desy., Mirzanie, Hanifah. (2009). Obgynacea. Yogyakarta: Tosca. Laila, 2011. Buku Pintar Menstruasi. Yogyakarta: Buku Biru.

Mansur, Herawati. (2009). Psikologi Ibu dan Anak Untuk Kebidanan. Jakarta: Salemba Medika. 190 halaman.

Manuaba. (2009). Memahami Kesehatan Reproduksi Wanita. Jakarta: EGC. 287 halaman.

Marlinda, Rofli., Rosalina., Purwaningsih, Puji. (2013). Pengaruh Senam Dismenore Terhadap Penurunan Dismenore pada Remaja Putri di Desa Sidoharjo Kecamatan Pati. Jurnal Keperawatan Maternitas Volume I. Fakultas Ilmu Keperawatan dan Kesehatan Universitas Muhammadiyah, Semarang

McDonald, Sandra., Winson, V. Nicola. (2009). Kamus Kebidanan Bergambar. Jakarta: EGC. 549 halaman.

Meryn, Siegfried. (2005). Hidup Sehat 100 Tahun. Jakarta: Pustaka Obor. 214 halaman.

Mitayani. (2011). Asuhan Keperawatan Maternitas. Jakarta: Salemba Medika. 280 halaman. 
Ningsih, Ratna. (2011). Efektifitas Paket Pereda Terhadap Intensitas Nyeri Pada Remaja Dengan Dismenore di SMAN Curup. Tesis Magister, Fakultas Ilmu Keperawatan Universitas Indonesia, Jakarta.

Notoatmodjo, S. (2012). Metodologi Penelitian Kesehatan. Jakarta: Rineka Cipta. 243 halaman.

Perry, Potter. (2005). Fundamental Keperawatan edisi 7. Jakarta: EGC. 385 halaman.

Pinem, Saroha. (2009). Kesehatan Reproduksi dan Kontrasepsi. Jakarta: TIM. 450 halaman.

Prawirohardjo, Sarwono. (2009). Ilmu Kandungan. Jakarta: Yayasan Bina Pustaka. 716 halaman.

Purwati, Noviana. (2011). Hubungan Pengetahuan dan Stres dengan Dismenorea pada Siswi Kelas XI SMA Negeri Kotagajah. KTI Diploma, Poltekkes Kemenkes, Tanjungkarang.

Saryono \& Sejati. (2009). Sindrom Premenstruasi. Yogyakarta: Nuna Medika.

Sibagariang, Eva Elya., Pusmaika, Rangga., Rismalinda. (2010). Kesehatan Reproduksi Wanita. Jakarta: TIM. 237 halaman.

Stoppard, Miriam. (2010). Panduan kesehatan Keluarga. Jakarta: Erlangga. Suparman \& Sentosa, (2011). Premenstrual Syndrome. Jakarta: EGC.

Taylor. (1994). Serotonin Levels and Pletelet Uptake During Premenstrual Tension. Neuropsychology. 